Article

\title{
Environmentally Sustainable Flame Retardant Surface Treatments for Textiles: The Potential of a Novel Atmospheric Plasma/UV Laser Technology
}

\author{
A. Richard Horrocks * (D), Sara Eivazi, Maram Ayesh and Baljinder Kandola ${ }^{\mathbb{D}}$ \\ IMRI, University of Bolton, Bolton BL3 5AB, UK; sara.aivazi@gmail.com (S.E.); mwa1res@bolton.ac.uk (M.A.); \\ b.kandola@bolton.ac.uk (B.K.) \\ * Correspondence: a.r.horrocks@bolton.ac.uk; Tel.: +44-1204-903831
}

Received: 7 April 2018; Accepted: 8 May 2018; Published: 14 May 2018

\begin{abstract}
Conventional flame retardant (FR) application processes for textiles involve aqueous processing which is resource-intensive in terms of energy and water usage. Recent research using sol-gel and layer-by-layer chemistries, while claimed to be based on more environmentally sustainable chemistry, still require aqueous media with the continuing problem of water management and drying processes being required. This paper outlines the initial forensic work to characterise commercially produced viscose/flax, cellulosic furnishing fabrics which have had conferred upon them durable flame retardant (FR) treatments using a novel, patented atmospheric plasma/Ultraviolet (UV) excimer laser facility for processing textiles with the formal name Multiplexed Laser Surface Enhancement (MLSE) system. This system (MTIX Ltd., Huddersfield, UK) is claimed to offer the means of directly bonding of flame retardant precursor species to the component fibres introduced either before plasma/UV exposure or into the plasma/UV reaction zone itself; thereby eliminating a number of wet processing cycles. Nine commercial fabrics, pre-impregnated with a semi-durable, proprietary FR finish and subjected to the MLSE process have been analysed for their flame retardant properties before and after a $40{ }^{\circ} \mathrm{C} 30 \mathrm{~min}$ water soak. For one fabric, the pre-impregnated fabric was subjected to a normal heat cure treatment which conferred the same level of durability as the plasma/UV-treated analogue. Thermogravimetric analysis (TGA) and limiting oxygen index (LOI) were used to further characterise their burning behaviour and the effect of the treatment on surface fibre morphologies were assessed. Scanning electron microscopy indicated that negligible changes had occurred to surface topography of the viscose fibres occurred during plasma/UV excimer processing.
\end{abstract}

Keywords: surface; textiles; cellulosic; viscose; linen; flame retardant; plasma; ultraviolet; durability; phosphorus; nitrogen; polyurethane; thermal analysis; scanning electron microscopy

\section{Introduction}

\subsection{Background}

It is almost 30 years ago that environmental concerns were raised with regard to flame retardants, originally in respect to the potential release of polybrominated dioxins during the incineration of polybrominated diphenyls and diphenyl ethers [1]. Since that time these concerns have increased to the extent that in recent years there has been much interest in developing environmentally sustainable, surface flame retardant treatments to textiles as potential replacements for those currently used based on halogen or formaldehyde-based chemistry [2,3]. Coincidently, these concerns have overlapped with the regulatory UK demand that since 1988 all domestic furnishing fabrics shall be resistant to both a lighted cigarette and a simulated match [4]. In the latter case, the furnishing fabric must be exposed 
to flame over a specified unmodified, polyurethane foam and the fabric should be sufficiently flame retardant to resist ignition of both fabric and foam. During the intervening period, back-coating fabrics with organobromine/antimony III oxide formulations has become a principal means of enabling fabrics comprising all fibre types to pass the regulatory requirements [4]. Not surprisingly, given the associated environmental concerns, pressures to move away from such treatments continue to mount.

Recent interest has focussed on a number of novel surface technologies based on nanoparticle, sol-gel and layer-by-layer, as well as atmospheric plasma surface depositions fully reviewed elsewhere [5]. The potential success of these surface treatments depends on a number of factors including whether the textile behaviour is thermally thin or thermally thick, what the minimal flame retardant, active species (e.g., phosphorus, nitrogen, silicon, etc.) levels are required to yield an acceptable level of flame retardancy with appropriate durability requirements. Any successful treatment should have minimal influence on other desirable fibre and fabric properties and of course be cost-effective.

While intumescent treatments have received considerable attention in the past, like those based on sol-gel treatments, they are often challenged by having poor wash durability [5,6]. Layer-by-layer treatments applied to cotton and cotton/polyester blends, however, have recently demonstrated acceptable self-extinguishing properties during vertical fabric strip testing after a defined washing procedure. Notable among these are the recently published results of Grunlan et al. [7,8]. All the above recent surface technologies are based on aqueous precursor treatments with the associated need for energy-intensive drying processes.

\subsection{Atmospheric Plasma Treatments}

In attempts to develop continuous processes requiring lower need for water-based processing, the advent of atmospheric plasma to continuous, open-width fabric processing equipment offers the opportunity of "dry" textile finishing with the consequent minimization of water requirements, effluent production and expensive drying processes [9]. This has created interest in its application to conferring flame retardancy in addition to other novel effects, such as improved fabric handle and increased dye uptake [10].

Of the little work published to date using atmospheric plasma, work in our laboratories has shown that deposition of silicon-based species on textile surfaces can significantly improve their flame retardancy defined in terms of improved flash fire resistance [11]. This improvement of flash fire resistance was observed on pure cotton, Proban ${ }^{\circledR}$ (Solvay, Brussels, Belgium)-treated cotton and Nomex ${ }^{\circledR}$ (DuPont, Wilmington, DE, USA) aramid fabrics. Subsequent work of Tata et al. [12] showed that polyester fabrics could be etched initially by cold oxygen plasma and then finished with hydrotalcite, nanometric titania and silica aqueous suspensions to give improved fire performance levels, even after washing in demineralised water at $30{ }^{\circ} \mathrm{C}$ for $30 \mathrm{~min}$. A subsequent study [13] used plasma surface activation combined with nano-montmorillonite clay deposition to improve the thermal stability of fabrics in air. Totolin et al. [14] have reported grafting/crosslinking of sodium silicate layers onto viscose and cotton flannel substrates by using atmospheric pressure plasma which increased fabric burning times during $45^{\circ}$ testing, although as recognised also by Edwards et al. [15], additional phosphorus as a phosphoramidate was necessary to achieve better levels of flame retardancy. Unfortunately, while char levels were increased, flame self-extinguishability during vertical fabric testing was not achieved and correlated with the still low phosphorus levels present.

\subsection{A Combined Atmospheric Plasma/UV Laser or Multiplexed Laser Surface Enhancement (MLSE) System}

A recently developed and patented, available as a full commercial process by MTIX Ltd., Huddersfield, UK [16], exploits the simple principle that atmospheric plasma treatment alone is insufficient to activate adjacent fibre and flame-retardant species and that a second high energy source sufficient to form strong FR-fibre chemical bonds, offers a means to this. In the MLSE process, this latter is a $308 \mathrm{~nm}$ UV excimer laser able to break single covalent bonds (C-C, C-O, C-N, etc.) in 
both flame-retardant precursor and fibre thereby increasing the chance of interaction. In principle, this system offers the means of eliminating a number of wet processing cycles normally associated with textile finishing processes [17] since the whole process is undertaken under dry conditions with no washing off requirements or other liquid effluents. The patent [16] also identifies the ability of the Multiplexed Laser Surface Enhancement (MLSE) system to introduce properties of hydrophilicity, hydrophobicity, improved dyeability and anti-microbial properties to textiles as well as specifically claiming that flame retardancy may be introduced either by pre-impregnating/coating prior to plasma/UV or by introduction of volatile/aerosol flame retardant precursors into the plasma zone. Current commercially-available equipment enables textile fabrics up to $2 \mathrm{~m}$ in width to be continuously processed up to speeds of $20 \mathrm{~m} / \mathrm{s}$. Figure $1 \mathrm{a}, \mathrm{b}$ show a typical machine based on this technology and a schematic view of the process respectively.

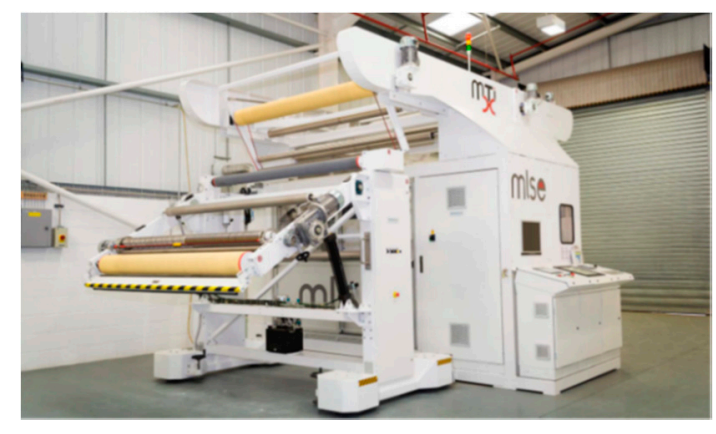

(a)

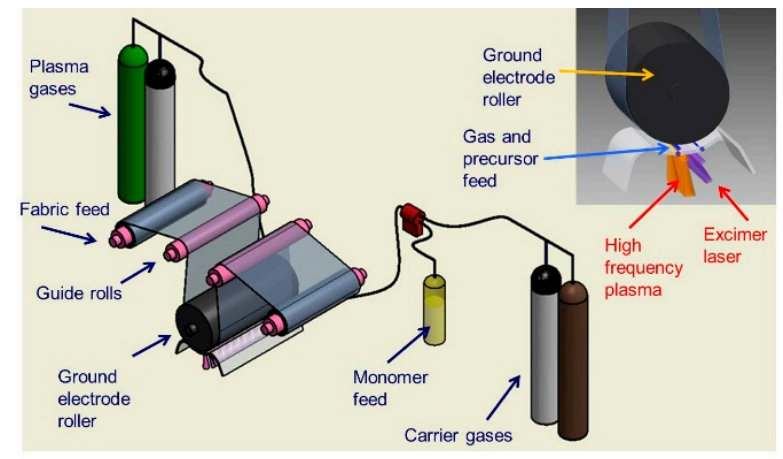

(b)

Figure 1. Multiplexed Laser Surface Enhancement (MLSE) system for open-width, textile fabric processing (reproduced with permission from MTIX Ltd., Huddersfield, UK).

The process exploits a number (typically up to four) of dielectric barrier discharge (DBD) plasma heads located so that one or both sides of a fabric may be treated simultaneously. Associated with each head is a UV excimer laser beam traversing the reaction zone created by the plasma discharge across the fabric. Figure $1 \mathrm{~b}$ and the right-hand insert shows schematically the fabric pathway travelling over one plasma/UV head assembly. Plasma atmospheres may comprise nitrogen, argon and carbon dioxide alone, mixed together or compositions containing small amounts (e.g., up to 20\%) of oxygen.

Exploratory work to date in the commercial environment has shown that attempts to research and develop novel FR treatments that may replace conventional back-coatings and chemically-based flame-retardant treatments for both cotton and wool fabrics (and respective blends) have met with some success but have been based entirely on trial and error processing. Furthermore, at a subjective level, the MLSE process developers are confident that no or minimal damage to the textile fibres occurs during plasma/UV exposure. However, there has been no research into process at a scientific level and this paper presents the first part of recent work at the University of Bolton in which we attempt to undertake a forensic analysis of a range of successful, commercially processed fabrics to analyse the quality of flame retardancy being introduced by the MLSE system in order to understand the process and compare their behaviour with similar, more conventionally treated fabrics. Furthermore, there is the need to determine whether or not any fibre surface damage accompanies the process.

This paper will analyse a number of proprietary viscose/linen, cellulosic blend, furnishing fabrics in terms of the levels of flame retardancy achieved and their durability to the statuary durability requirement of being able to withstand a $30 \mathrm{~min}, 40{ }^{\circ} \mathrm{C}$ water soak durability test [4]. The potential surface morphological changes occurring to surfaces of the viscose majority fibres are examined by scanning electron microscopy, which are considered to be the more sensitive of the two fibres present because of the absence of lignin present in the flax fibres [18]. 


\section{Materials and Methods}

\subsection{Materials and Preparation}

Nine jacquard woven, cellulosic-blended, commercial fabrics (see Table 1) were pre-impregnated with a proprietary organophosphorus- and nitrogen-containing flame retardant (FR) formulation prior to plasma/UV treatment $(2 \mathrm{~kW}$ and $308 \mathrm{~nm}$ ) under an inert atmosphere (see below) at various add-ons. Because of commercial sensitivity, the exact chemical genus of the flame retardant cannot be divulged suffice it to state that it functions as a typical condensed phase retardant when applied directly with or without a subsequent heat cure. The cellulosic fabrics varied in terms of the jacquard design (e.g., check versus stripes), fabric construction and area density and were believed to comprise blended yarns of viscose and flax fibres with the former in the majority. Subsequent scanning electron micrographs confirmed this assumption (see Section 3.3). When normally applied by a pad-dry process, the proprietary flame retardant (FR) formulation is not durable to water soaking, although if heat-cured some level of water soak durability is achieved. This was demonstrated by applying the commercial flame retardant at a nominal $6 \%$ add-on using a laboratory pad-mangle system to an untreated sample 2 fabric via a simple pad-dry process (sample $2 \mathrm{a}$ ) and a pad-dry-cure $\left(3 \mathrm{~min}\right.$ at $150{ }^{\circ} \mathrm{C}$ ) process (sample $2 b$ ). Percentage add-ons of the flame-retardant formulation of fully treated fabrics were calculated by comparing the area densities of respective fabrics that had no FR pre-impregnation with those that had been plasma/UV-exposed before the water soak. Fabric types, respective area densities and flame-retardant add-ons are presented in Table 1.

Table 1. Area densities and percentage add-ons of flame retardant.

\begin{tabular}{ccccc}
\hline Fabrics & Treatment & Sample & $\begin{array}{c}\text { Area Density, } \\
\text { g/m } \mathbf{m}^{2}\end{array}$ & $\begin{array}{c}\text { Plasma/UV-Exposed Fabric } \\
\text { Add-Ons, } \text { (Before Water Soaking) }\end{array}$ \\
\hline 1. & Pad/dry/plasma & Cellulosic blend & 413 & 13.8 \\
2. & Pad/dry/plasma & Cellulosic blend & 417 & 12.7 \\
2a. & Pad/dry & & $6.0^{*}$ \\
2b. & Pad/dry/cure (150 ${ }^{\circ}$ C) & & $6.0 *$ \\
3. & Pad/dry/plasma & Cellulosic blend & 406 & 12.1 \\
4. & Pad/dry/plasma & Cellulosic blend & 421 & 8.5 \\
5. & Pad/dry/plasma & Cellulosic blend & 410 & 13.4 \\
6. & Pad/dry/plasma & Cellulosic blend & 388 & 11.1 \\
7. & Pad/dry/plasma & Cellulosic blend & 332 & 27.7 \\
8. & Pad/dry/plasma & Cellulosic blend & 337 & 23.0 \\
9. & Pad/dry/plasma & Cellulosic blend & 447 & 14.0 \\
\hline
\end{tabular}

Note: * add-on is a nominal value calculated during pad application.

\subsection{Atmospheric Plasma/UV Laser (MLSE) Conditions}

The exact plasma/UV conditions were determined as a consequence of the company having undergone its own trials and cognizant of the need to minimize any associated fibre surface degradation. Thus, the plasma power used was $2 \mathrm{~kW}$ and plasma gas 95\% nitrogen $/ 5 \% \mathrm{CO}_{2}$. The excimer laser power was $650 \mathrm{~mJ}$. The process speed was $20 \mathrm{~m} / \mathrm{min}$. Plasma/UV-exposed on both sides of the fabrics using one single head each side (see Figure 1b). Since the plasma beam has a width of $30 \mathrm{~mm}$ [16], then it may be calculated that the time of exposure of a given area of fabric will be only about $0.1 \mathrm{~s}$.

\subsection{Flammability Testing}

Plasma/UV exposed fabrics were examined for their ability to pass the Source 1 (simulated match) ignition requirements of BS 5852: 1979: Part1 as required by the current UK regulations for furniture and furnishing fabrics [4]. In this paper we have used a simulation of this test, first devised in industry over 25 years ago and described in full elsewhere [19]. In summary, this test combines the fabric 
and foam sample dimensions of the BS5438: 1989: Test 2 vertical strip method with a $20 \mathrm{~s}$ front face, flame application time as defined in BS5852: Part 1: Source 1 (see Figure 2).

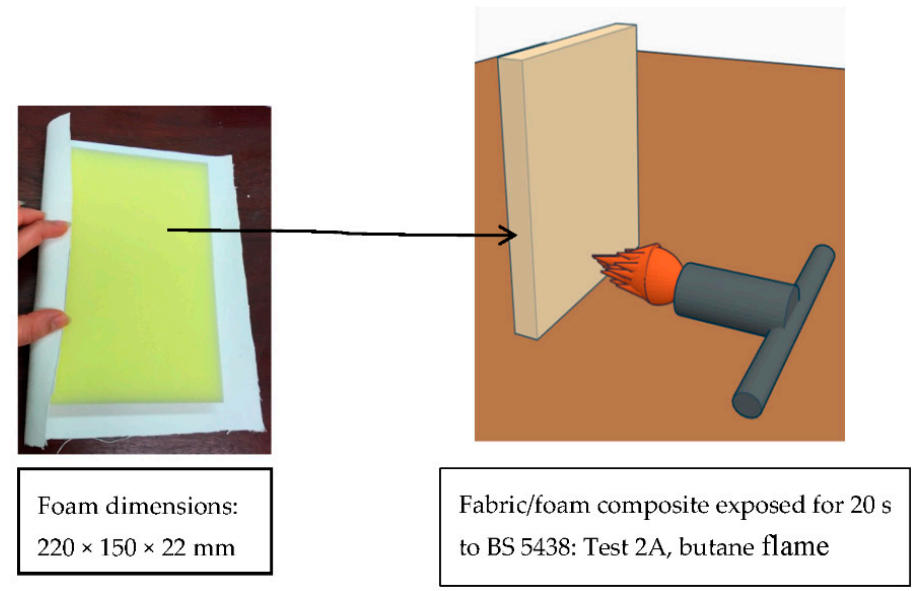

Figure 2. Schematic diagram of the simulated match test for BS 5852: 1979: Part 1: Source 1 using a modification of BS 5438: 1989: Test 2A.

In this simulated test, a piece of non-flame retardant, flexible polyurethane (PU) foam of $220 \times 150 \times 22 \mathrm{~mm}$ (density of $22 \mathrm{~kg} / \mathrm{m}^{3}$ ) is covered by a flame retarded fabric sample with the foam adjacent to the reverse side. This composite is mounted in the Test 2 sample frame with the fabric face towards the gas burner in the horizontal mode (Test 2A, face ignition condition) with its tip $17 \mathrm{~mm}$ from the fabric surface. With a vertical flame height adjusted to $40 \mathrm{~mm}$ as specified in BS 5438, the flame is applied to the composite face for $20 \mathrm{~s}$ and then removed. If the composite yields afterflame times (AFT) $>2$ min or produces externally detectable amounts of smoke, heat or afterglow $2 \mathrm{~min}$ after removal of the ignition source, a "fail" is recorded for the test result, otherwise a "pass" result is reported. All FR-treated, plasma/UV-exposed samples (including samples 2a and 2b) were subjected to this test before and after the mandatory $40{ }^{\circ} \mathrm{C}, 30 \mathrm{~min}$ water soak requirement [4]. Fabric damaged lengths $(\mathrm{FaDL})$ were determined by simple measurement as were the depths of foam damage (FoDD) after each test.

Limiting oxygen index values were recorded using a Fire Testing Technology (East Grinstead, UK) test equipment according to the ASTM D2863 method for thin materials including textiles.

All water-soaked fabrics were dried in the open laboratory and then stored in a desiccator prior to their being tested both to the simulated match test and for LOI in the open laboratory.

\subsection{Thermal Analysis}

TGA experiments were performed using a SDT 2960 Simultaneous DTA-TGA (TA Instruments, New Castle, DE, USA). Samples with weights in the range 5-10 mg were placed in an open platinum pan heated from 50 to $700{ }^{\circ} \mathrm{C}$ in air with a heating rate of $10{ }^{\circ} \mathrm{C} \mathrm{min}-1$. Temperatures of onset of mass loss (determined at $5 \%$ mass loss), $\mathrm{T}_{\text {onset }}$, were determined as were temperatures of maximum mass loss during volatilisation, $\mathrm{T}_{\max 1}$, and char oxidation, $\mathrm{T}_{\max 2}$. Residues at 400 and $550{ }^{\circ} \mathrm{C}$ were recorded, which respectively indicated maximum char yields prior to their oxidation and after oxidation in air.

\subsection{Scanning Electron Microscopy and EDX}

Samples of commercial sample 6 in untreated and flame retardant impregnated, plasma/UV laser-treated fabrics, before and after a water soak were coated with gold using a Quorum Technologies (Lewes, UK) SC7620 sputter coater and then examined using a Hitachi (Tokyo, Japan) S-3400N scanning electron microscope at a beam voltage of either between 2 or $5 \mathrm{kV}$. 


\section{Results}

\subsection{Flammability Testing}

The percentage add-on results are listed in Table 1 before water soaking. All results for fabric/foam composite testing and respective fabric limiting oxygen index (LOI) results are listed in Table 2. All fabrics without any pre-impregnation with the flame-retardant formulation failed the simulated match test over unmodified PU foam in that after extinction of the igniting flame, all fabrics continued to burn together with the underlying foam and the composites required to be extinguished using a water spray. The LOI values of these untreated fabrics (Non-FR) are listed in Table 2 and not surprisingly are typically in the range 19.8-19.3 vol \% observed for $100 \%$ cellulosic fabrics.

Table 2. Simulated match test (Source 1, BS 5852) and LOI results.

\begin{tabular}{|c|c|c|c|c|c|c|c|c|c|c|}
\hline \multirow{4}{*}{ Fabrics } & \multirow{4}{*}{$\begin{array}{c}\text { Initial Area } \\
\text { Density } \\
\left(\mathrm{g} / \mathrm{m}^{2}\right)\end{array}$} & \multicolumn{3}{|c|}{$\begin{array}{c}\text { Simulated Match Test } \\
\text { over PU Foam Before } \\
\text { Water Soaking }\end{array}$} & \multicolumn{4}{|c|}{$\begin{array}{l}\text { Simulated Match Test over PU } \\
\text { Foam After Water Soaking }\end{array}$} & \multicolumn{2}{|c|}{ LOI, vol \% } \\
\hline & & \multirow{3}{*}{ AFT, s } & \multirow{3}{*}{$\begin{array}{c}\text { FaDL, } \\
\text { mm }\end{array}$} & \multirow{3}{*}{$\begin{array}{l}\text { FoDD, } \\
\mathrm{mm}\end{array}$} & \multirow{3}{*}{ AFT, s } & \multirow{3}{*}{$\begin{array}{c}\text { FaDL, } \\
\mathrm{mm}\end{array}$} & \multirow{3}{*}{$\begin{array}{l}\text { FoDD, } \\
\text { mm }\end{array}$} & \multirow{3}{*}{$\begin{array}{l}\text { Non } \\
\text { FR }\end{array}$} & \multicolumn{2}{|c|}{ FR/Plasma/UV } \\
\hline & & & & & & & & & Before Soak & After Soak \\
\hline & & & & & & & & & \multicolumn{2}{|c|}{ Water-Soaking } \\
\hline 1. & 413 & 0 & 105 & 5 & 5 & 119 & 10 & 18.9 & 28.4 & 22.8 \\
\hline 2. & 417 & 0 & 84 & 9 & 7 & 116 & 9 & 19.3 & 29.8 & 24.7 \\
\hline $2 a$. & & 2 & 85 & 5 & Fully burnt & - & - & 19.3 & 31.2 & 19.7 \\
\hline $2 b$. & & 0 & 72 & 2 & 13 & 110 & 10 & 19.3 & 31.2 & 21.9 \\
\hline 3. & 406 & 0 & 69 & 9 & 15 & 165 & 9 & 19.0 & 29.7 & 22.5 \\
\hline 4. & 421 & 0 & 73 & 14 & 11 & 120 & 9 & 18.8 & 29.6 & 23.2 \\
\hline 5. & 410 & 0 & 78 & 10 & 23 & 170 & 8 & 18.9 & 29.9 & 22.9 \\
\hline 6. & 388 & 0 & 94 & 9 & 11 & 125 & 9 & 18.9 & 29.5 & 23.3 \\
\hline 7. & 332 & 0 & 92 & 9 & 1 & 112 & 12 & 19.1 & 32.1 & 25.4 \\
\hline 8. & 337 & 0 & 82 & 8 & 1 & 110 & 9 & 19.2 & 32.2 & 25.6 \\
\hline 9. & 447 & 0 & 102 & 9 & 18 & 156 & 14 & 19.0 & 29.8 & 22.9 \\
\hline
\end{tabular}

Key: AFT = Afterfame time; FaDL = fabric damaged length; FoDD = Foam damaged depth.

The results for sample 2a show that a simple pad-dry FR application is not durable to the $40{ }^{\circ} \mathrm{C}$ water soak as expected, since the fabric when tested over PU foam before soaking passes the simulated match test and has LOI $=31.2 \mathrm{vol} \%$, whereas afterwards it fails and LOI reduces to $19.3 \mathrm{vol} \%$, the same as the untreated fabric. However, the application of a $3 \mathrm{~min}, 150{ }^{\circ} \mathrm{C}$ cure shows that a degree of water soak durability has been achieved since sample $2 \mathrm{~b}$ after soaking passes the simulated match test with LOI $=21.9$ vol \%.

All flame retardant, plasma/UV-treated fabrics passed the simulated match test before water-soaking with afterflame times (AFT) of $0 \mathrm{~s}$ and damaged lengths (FaDL) $\leq 102 \mathrm{~mm}$. After water soaking, all samples once again passed with afterflame times $\leq 23$ s and damaged lengths $\leq 165 \mathrm{~mm}$, which reflect the partial loss of flame retardant during the $30 \mathrm{~s}, 40{ }^{\circ} \mathrm{C}$ water soak. However, the fabric/foam composites still were deemed to have passed the simulated match test (and hence BS 5858: 1979: Source 1) since afterflame times were $\leq 120 \mathrm{~s}$ and damaged lengths did not extend to the edges of the fabric sample, $180 \mathrm{~mm}$ above the impinging flame centre. Typical images of all burnt fabric/foam composite samples impregnated with the FR, plasma/UV-treated and then subjected to a $30 \mathrm{~min}, 40^{\circ} \mathrm{C}$ water soak are represented by that for sample 6 fabric shown in Figure $3 a$ for damaged lengths before and after soaking and in Figure $3 b$ for PU foam samples behind respective specimens of sample 2.

Figure 4 shows a plot of limiting oxygen index (LOI) versus damaged length (FaDL) before the water soak treatment and Figure 5 after the $30 \mathrm{~min}, 40^{\circ} \mathrm{C}$ water-soaked for fabrics listed in Table 2. It is evident that there is no real trend other than that all fabrics before water-soaking have LOI values $>28$ vol \% and damaged lengths $\leq 105 \mathrm{~mm}$. After water-soaking, however, Figure 5 shows there is a definite initial trend such that when the LOI value drops below 26 vol \%, there appears to be an almost inverse linear relationship with increasing damaged length occurring until a value of 23 vol \% 
is reached. While LOI changes little as the damaged length increases further, even for LOI values of about $22.5 \mathrm{vol} \%$, fabrics subjected to the simulated match test still give acceptable values $\leq 180 \mathrm{~mm}$.

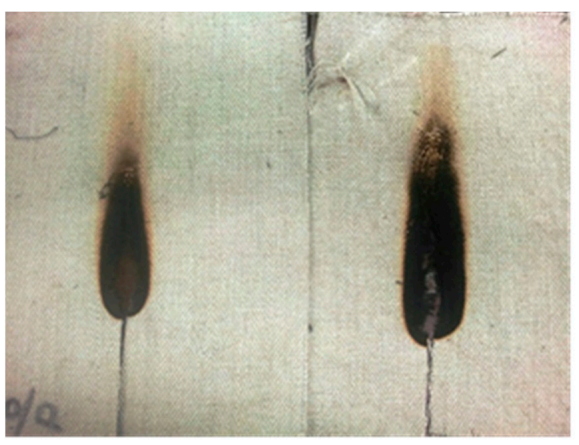

(a)

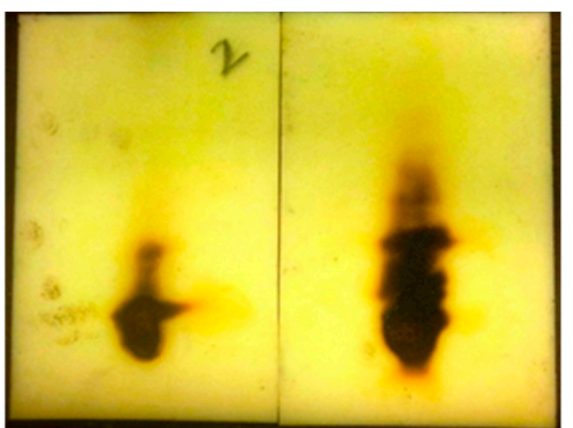

(b)

Figure 3. Composite fabric/foam specimens after small-scale simulated match testing (a) sample 6 fabric; (b) PU foam underlying sample 2, before (left) and after (right) water-soaking.

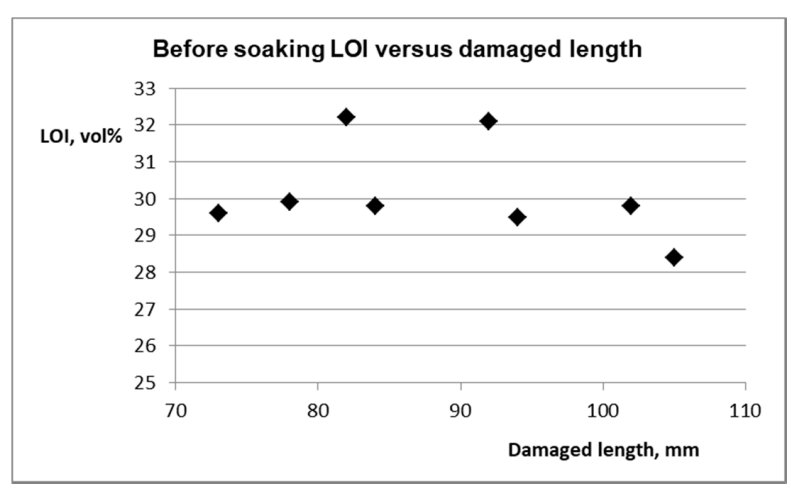

Figure 4. LOI versus damaged length for the plasma/UV-exposed fabrics.

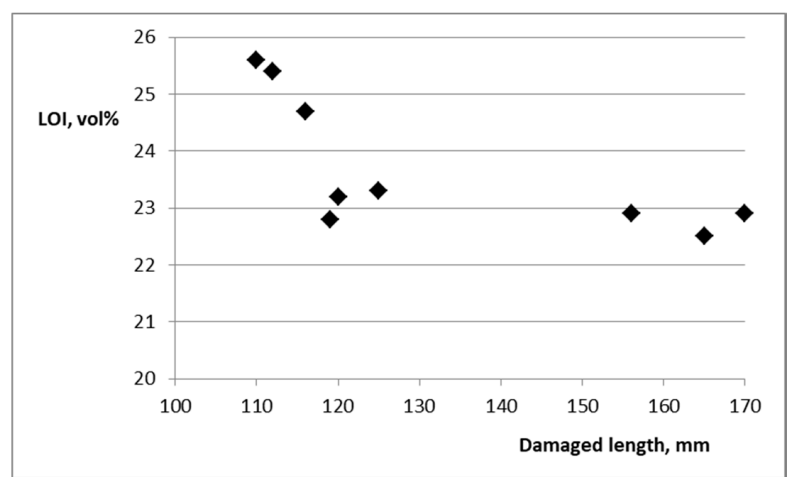

Figure 5. LOI versus damaged length for the $30 \mathrm{~min}, 40{ }^{\circ} \mathrm{C}$ water-soaked, plasma/UV-exposed fabrics.

\subsection{Thermal Analysis}

Figure 6 shows typical TGA responses in air for woven twill fabric 1 comprising viscose and linen, for untreated and FR-impregnated, plasma/UV-exposed samples before water-soaking and after water soaking. The discontinuity in the untreated sample at about $450{ }^{\circ} \mathrm{C}$ is a consequence of the ignition of the cellulosic char at this temperature. The reduction in the onset temperature of major volatilisation and related maximum rate loss temperature $\left(\mathrm{T}_{\max 1}\right)$ in the $300-350{ }^{\circ} \mathrm{C}$ region and increase in char evident at about $450^{\circ} \mathrm{C}$ are a consequence of the FR present. 


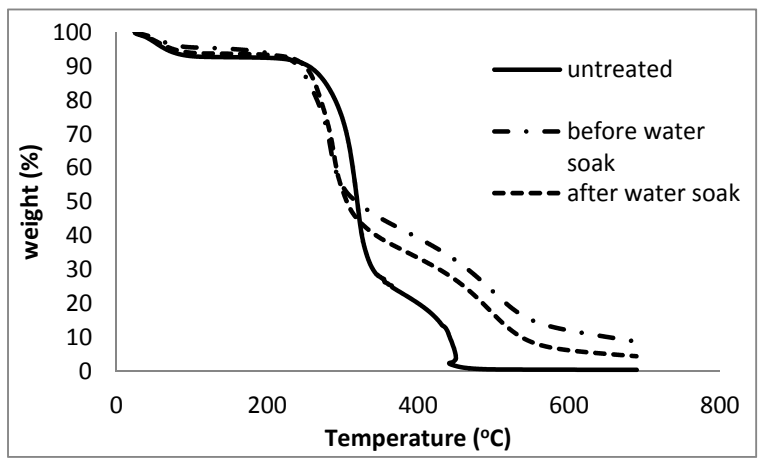

Figure 6. TGA response in air of fabric 1, untreated and after flame retardant, plasma/UV- exposed before and after water-soaking.

These effects are typical of the behaviour of condensed phase active phosphorus- and nitrogen-containing flame retardants present on cellulosic fibres first observed by Tang and Neill over 50 years ago [20] and so indicate that the plasma/UV laser treatment has not influenced the flame-retardant mechanism. After water-soaking, the apparent $\mathrm{T}_{\max 1}$ value increases slightly and the increase in char is reduced as a consequence of some loss of FR during water-soaking.

Each of the nine untreated fabrics is cellulosic-based and of similar area density and construction. However, they have different manufacturing histories and, as jacquard designs (e.g., check versus stripe), have differently dyed weft and warp yarns as a consequence. Such differences often promote slight variations in thermal decomposition data. Table 3 lists all the TGA data the nine fabrics and includes the maximum volatilisation and char oxidation mass loss rate temperatures, $\mathrm{T}_{\max 1}$ and $\mathrm{T}_{\max 2}$ respectively. Residue values at 400 and $550{ }^{\circ} \mathrm{C}$ are included which represent char levels before and after oxidation respectively. $\mathrm{T}_{\text {onset }}$ values are within a range of $57-86^{\circ} \mathrm{C}$ reflecting the onset of moisture loss with $\mathrm{T}_{\max 1}$ values covering a much smaller range of $330-340{ }^{\circ} \mathrm{C}$. This indicates that each of the untreated fabrics has a very similar decomposition behaviour in spite of their varying manufacturing histories. Maximum rate temperatures of char oxidation, $\mathrm{T}_{\max 2}$, are also similar covering the range $435-464{ }^{\circ} \mathrm{C}$, although in the $450-460{ }^{\circ} \mathrm{C}$ region, samples combust leaving virtually no residue $(\leq 1 \%)$.

Table 3. TGA data in air from each fabric, untreated and after plasma/UV exposure before and after water-soaking.

\begin{tabular}{|c|c|c|c|c|c|c|}
\hline & Samples & $\mathrm{T}_{\text {onset }}(5 \%$ Weight Loss) & $\mathrm{T}_{\max 1},{ }^{\circ} \mathrm{C}$ & $\mathrm{T}_{\max 2,}{ }^{\circ} \mathrm{C}$ & Residue at $400{ }^{\circ} \mathrm{C}, \%$ & Residue at $550{ }^{\circ} \mathrm{C}, \%$ \\
\hline \multirow{3}{*}{1.} & Untreated & 60 & 330 & 450 & 20 & 0.5 \\
\hline & Before soak & 147 & 334 & 500 & 39 & 15 \\
\hline & After soak & 67 & 320 & 496 & 33 & 8 \\
\hline \multirow{3}{*}{2.} & Untreated & 57 & 330 & 453 & 19 & 0.6 \\
\hline & Before soak & 91 & 333 & 500 & 37 & 13 \\
\hline & After soak & 79 & 317 & 494 & 31 & 7 \\
\hline \multirow{3}{*}{3.} & Untreated & 64 & 335 & 454 & 20 & 1 \\
\hline & Before soak & 89 & 333 & 500 & 38 & 14 \\
\hline & After soak & 78 & 326 & 500 & 31 & 6 \\
\hline \multirow{3}{*}{4.} & Untreated & 62 & 336 & 454 & 20 & 1 \\
\hline & Before soak & 168 & 294 & 498 & 42 & 19 \\
\hline & After soak & 85 & 320 & 497 & 34 & 10 \\
\hline \multirow{3}{*}{5.} & Untreated & 65 & 334 & 452 & 20 & 0.9 \\
\hline & Before soak & 107 & 336 & 500 & 40 & 16 \\
\hline & After soak & 91 & 317 & 491 & 32 & 7 \\
\hline \multirow{3}{*}{6.} & Untreated & 60 & 334 & 460 & 21 & 0.2 \\
\hline & Before soak & 116 & 333 & 500 & 41 & 17 \\
\hline & After soak & 113 & 319 & 496 & 35 & 10 \\
\hline
\end{tabular}


Table 3. Cont.

\begin{tabular}{|c|c|c|c|c|c|c|}
\hline & Samples & $\mathrm{T}_{\text {onset }}(5 \%$ Weight Loss) & $\mathrm{T}_{\max 1},{ }^{\circ} \mathrm{C}$ & $\mathrm{T}_{\max 2,}{ }^{\circ} \mathrm{C}$ & Residue at $400{ }^{\circ} \mathrm{C}, \%$ & Residue at $550{ }^{\circ} \mathrm{C}, \%$ \\
\hline \multirow{3}{*}{7.} & Untreated & 86 & 340 & 464 & 18 & 0 \\
\hline & Before soak & 191 & 302 & 500 & 40 & 15 \\
\hline & After soak & 216 & 312 & 500 & 37 & 11 \\
\hline \multirow{3}{*}{8.} & Untreated & 82 & 336 & 436 & 19 & 0 \\
\hline & Before soak & 217 & 331 & 497 & 42 & 19 \\
\hline & After soak & 225 & 307 & 497 & 35 & 8 \\
\hline \multirow{3}{*}{9.} & Untreated & 64 & 330 & 435 & 19 & 0 \\
\hline & Before soak & 136 & 342 & 494 & 40 & 16 \\
\hline & After soak & 82 & 321 & 494 & 37 & 12 \\
\hline
\end{tabular}

It is also evident that the behaviours of the flame-retardant formulation on all nine cellulose-based fabrics after FR impregnation and plasma/UV exposure before water soaking are similar in that the temperatures of maximum volatilisation, $\mathrm{T}_{\max 1}$, cover the range $294-342{ }^{\circ} \mathrm{C}$, (see Table 1 ), although when plotted as a function of add-on \% in Figure 7, a clear and expected inverse trend is observed. Again, this shows that the condensed phase mechanism of the applied flame retardant is not influenced by the plasma/UV exposure and that the shift to lower temperatures of $T_{\max 1}$ with increasing $F R$ add-on $\%$ is as expected.

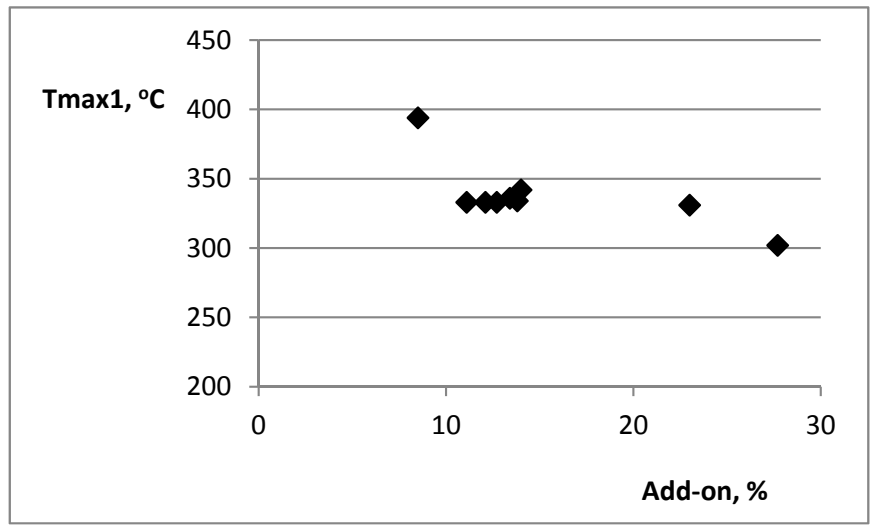

Figure 7. Plot of $\mathrm{T}_{\max 1}$ versus percentage add-on for fabrics before water-soaking.

After water soaking, the $\mathrm{T}_{\max 1}$ range is much less at $307-326^{\circ} \mathrm{C}$, suggesting only a small amount of loss of flame retardant has occurred. However, the reduced LOI values after water-soaking and increased damaged length values disagree with this conclusion, as does the effect of water soaking on char values at $450{ }^{\circ} \mathrm{C}$. Before water-soaking, the latter are in the range $37-42 \%$ whereas after water-soaking, 31-37\%, which clearly indicates that loss of some flame retardant has occurred, shown also by the difference in damaged lengths for water-soaked, sample 6 specimens shown in Figure 3a.

\subsection{Fibre Surface Morphologies}

Scanning electron micrographs in Figure 8a,b respectively show the typical striated morphology of viscose fibres and a much coarser flax fibre, as a bundle ultimate fibres, in fabric sample 6 prior to any flame retardant impregnation and plasma/UV exposure. The former appear to be in the majority judging by their dominance in the SEM images at lower magnifications. The viscose fibres will have typical skin-core structures with both phases showing lower levels of crystallinity [21-23] than the flax fibres present [22,24]. This coupled with the fact that the flax fibre ultimate bundles will still have lignin present $[18,25]$ suggests that these will be more resistant to surface morphological damage than the former. Consequently, the major focus here will be examination of the viscose fibre surfaces for topographical changes generated by their exposure to plasma/UV energy. Figure $8 \mathrm{c}$ shows the same 
sample after flame-retardant treatment and plasma/UV laser treatment and Figure 8d shows the latter specimen after having been subjected to a $40{ }^{\circ} \mathrm{C}$ water soak.

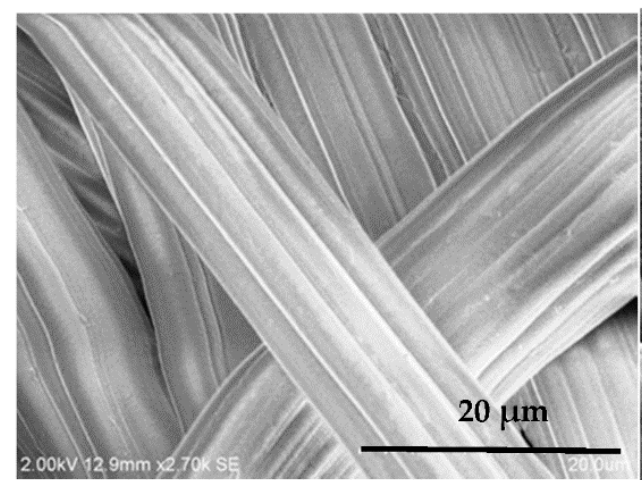

(a)

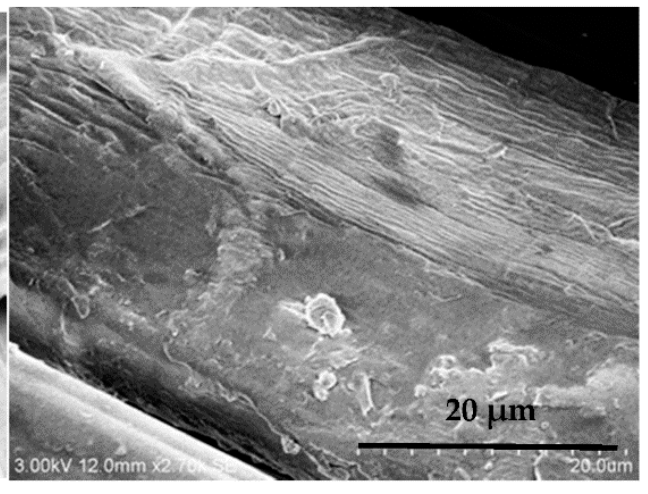

(b)

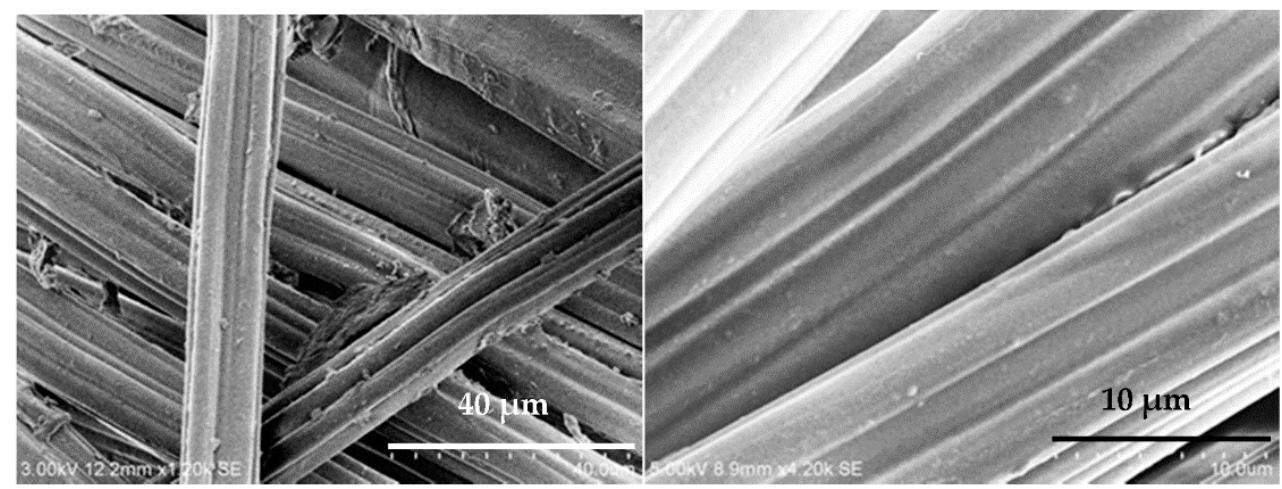

(c)

(d)

Figure 8. SEM micrographs of sample 6 comprising both viscose and flax fibres; (a) no treatment-viscose fibres; (b) no treatment-flax fibre bundle; (c) flame retardant impregnation and subsequent plasma/UV laser exposed viscose fibres and (d) as for (c) but after water-soaking at $40{ }^{\circ} \mathrm{C}$.

Relative to Figure $8 \mathrm{a}$, the viscose fibres pre-impregnated with flame retardant and plasma/UV-exposed show the presence of considerable surface debris, which after water soaking at $40{ }^{\circ} \mathrm{C}$, has largely been removed. The surfaces of viscose fibres in Figure $8 \mathrm{~d}$ are smooth and very similar to those untreated ones in Figure 5a, which would suggest that the exposure to plasma at $2 \mathrm{~kW}$ and UV at $308 \mathrm{~nm}$ in a 95\% nitrogen/5\% carbon dioxide atmosphere has had no observable etching effect at the magnification and resolution used. Such etching effects are well documented in the plasma literature for polyester and polypropylene fibre exposure under both inert and oxidising conditions, with the latter generating the greater level of surface erosion or etching [26]. There is very little literature with regard to the effect of plasma exposure on viscose fibre surfaces, whether under vacuum or atmospheric conditions and examples of the majority of these tend be in oxygenated atmospheres most often at low pressures $[27,28]$ where introduction of oxygenated functionalisation $[27,29]$ occurs as a precursor to surface morphological change [28]. Of the few studies in which nitrogen is used, there appears to be little or no observable changes to fibre surface morphologies under SEM examination [27,30]. Interestingly, Ibrahim et al. [31] claim to have observed that pretreatment of cotton, linen and viscose substrates with a $5 \mathrm{~kW}$ output atmospheric plasma under nitrogen applied for $45 \mathrm{~s}$ results in a remarkable increase in their nitrogen content, as a direct consequence of incorporation of nitrogen-rich polar functional groups, especially- $\mathrm{NH}_{2}$ groups at the modified fibre surface in addition to the inherent cellulosic-OH groups. Their SEM micrographs showed little evidence of surface damage to either viscose or linen fibres present. The fabrics in this work were exposed for much lower times 
of about $0.1 \mathrm{~s}$ and so based on this latter work, the level of surface damage and reaction to form nitrogen-containing compounds would be expected to be less by about two orders of magnitude.

\section{Discussion and Conclusions}

This paper has assessed the ability of a novel MLSE technology to confer an acceptable level of durability on a range of cellulosic, furnishing-grade fabrics to which a proprietary, non-durable flame retardant has been applied. Their ability to pass a simulated match test over PU foam, which is a requirement for UK domestic furnishing fabrics after a $30 \mathrm{~min}, 40^{\circ} \mathrm{C}$ water soak procedure, has been used as the measure of their behaviour in this respect. The proprietary flame retardant has been shown to be non-durable if applied simply by a pad-dry process, but is acceptably durable if then subjected to a $3 \mathrm{~min}, 150{ }^{\circ} \mathrm{C}$ cure and then tested after water-soaking.

The analysis of the resistance to ignition over PU foam of nine commercial FR-impregnated, cellulosic woven fabrics of slightly varying area density, shows that subjecting fabrics to the plasma/UV laser processing confers a similar, if not higher degree of water soak durability compared to the heat-cured control sample. LOI values before and after water soaking show that all fabrics after soaking had values $\geq 22.5 \mathrm{vol} \%$, which were greater than the value for the water-soaked, heat-cured sample $(21.9 \mathrm{vol} \%)$. Thermal analysis of the nine fabrics showed that the flame-retardant activity of the applied retardant was as expected for a typical condensed phase formulation and so had not been affected by exposure to the plasma/UV laser source.

Scanning electron microscopy indicated that negligible changes to surface topography of the viscose fibres occurred during plasma/UV excimer processing of the commercial viscose/linen blended fabrics. These results confirmed the assumptions made by the company that indeed surface damage during process is minimal, if not effectively zero.

Future work should attempt to model this commercial system using a laboratory plasma torch, previously described [11], in conjunction with an excimer laser with the aim of investigating the changes in surface chemistry using techniques such as X-ray photoelectron spectroscopy (XPS), radical trapping and electron paramagnetic resonance (EPR). The ultimate aim will be to assess possible mechanisms by which durability of flame retardant species present on the fabric or introduced into the plasma zone directly may be achieved in terms of the underlying chemical processes involved.

Author Contributions: A.R.H. and B.K. had overall responsibility for supervising the work and together with S.E. designed the experiments; S.E. undertook the sample preparation, flammability testing and TGA experiments and M.A. undertook all the scanning electron microscopy work; A.R.H. and B.K. undertook the analysis of results and A.R.H. wrote the paper.

Acknowledgments: The authors wish to thank the Cotton Industry War Memorial Trust for sponsoring the PhD programmes of S.E. and M.A. and to Messrs Graham Downhill and Pravin Mistry of MTIX Ltd., Huddersfield, England, for additional financial assistance, use of the MLSE equipment and supply of commercial fabrics.

Conflicts of Interest: The authors declare that although MTIX Ltd., were part sponsors of this project and supplied the commercial fabrics, they had no role in the design of the study; in the collection, analyses, or interpretation of data; in the writing of the manuscript, and in the decision to publish the results.

\section{References}

1. McAllister, D.L. Brominated flame retardants: Current issues and future prospects. In Flame Retardants '92; The Plastics and Rubber Institute, Ed.; Elsevier: London, UK, 1992; pp. 149-154, ISBN 1-85166-758-X.

2. Horrocks, A.R. Flame retardant challenges for textiles and fibres: New chemistry versus innovatory solutions. Polym. Degrad. Stab. 2011, 96, 377-392. [CrossRef]

3. Horrocks, A.R. Overview of traditional flame-retardant solutions. In Update on Flame Retardant Textiles: State of the Art, Environmental Issues and Innovative Solutions; Alongi, J., Horrocks, A.R., Carosio, F., Malucelli, G., Eds.; Smithers Rapra: Shawbury, UK, 2013; pp. 123-178.

4. Consumer Protection Act (1987), the Furniture and Furnishings (Fire) (Safety) Regulations, 1988, SI1324 (1988), 1988; HMSO: London, UK, 1988; Amended in 1989, 1993 and 2010. 
5. Alongi, J.; Carioso, F.; Malucelli, G. Smart (nano)coatings. In Update on Flame Retardant Textiles: State of the Art, Environmental Issues and Innovative Solutions; Alongi, J., Horrocks, A.R., Carosio, F., Malucelli, G., Eds.; Smithers Rapra: Shawbury, UK, 2013; pp. 263-318.

6. Horrocks, A.R. Flame Retardant finishes. In Textiles: Current Developments and Future Trends; Bahners, T., Mittal, K., Eds.; Scrivener Publishing LLC: Beverly, MA, USA, 2017; pp. 69-128.

7. Leistner, M.; Abu-Odeh, A.A.; Rohmer, S.C.; Grunlan, J.C. Water-based chitosan/melamine polyphosphate multilayer nanocoating that extinguishes fire on polyester-cotton fabric. Carbohydr. Polym. 2015, 130, 227-232. [CrossRef] [PubMed]

8. Haile, M.; Leistner, M.; Sarwar, O.; Toler, C.M.; Henderson, R.; Grunlan, J.C. A wash-durable polyelectrolyte complex that extinguishes flames on polyester-cotton fabric. RSC Adv. 2016, 6, 33998-34004. [CrossRef]

9. Shishoo, R. (Ed.) Plasma Technologies for Textiles; Woodhead Publishing: Cambridge, UK, 2007.

10. Herbert, T. Atmospheric-pressure cold plasma processing technology. In Plasma Technologies for Textiles; Shishoo, R., Ed.; Woodhead Publishing: Cambridge, UK, 2007; pp. 79-128.

11. Horrocks, A.R.; Nazaré, S.; Masood, R.; Kandola, B.K.; Price, D. Surface modification of fabrics for improved flash-fire resistance using atmospheric pressure plasma. Polym. Adv. Technol. 2011, 22, 22-29. [CrossRef]

12. Tata, J.; Alongi, J.; Frache, A. Optimization of the procedure to burn textile fabrics by cone calorimeter: Part II. Results on nanoparticle-finished polyester. Fire Mater. 2012, 36, 527-537.

13. Carosio, F.; Alongi, J.; Frache, A. Influence of surface activation by plasma and nanoparticle adsorption on the morphology, thermal stability and combustion behavior of PET fabrics. Eur. Polym. 2011, 47, 893-902. [CrossRef]

14. Totolin, V.; Sarmadi, M.; Manolache, S.O.; Denes, F.S. Environmentally friendly flame-retardant materials produced by atmospheric pressure plasma modifications. J. Appl. Polym. Sci. 2012, 124, 116-122. [CrossRef]

15. Edwards, B.; El-Shafaei, A.; Hauser, P.; Malshe, P. Towards flame retardant cotton fabrics by atmospheric pressure plasma-induced graft polymerization: Synthesis and application of novel phosphoramidate monomers. Surf. Coat. Technol. 2012, 209, 73-79. [CrossRef]

16. Mistry, P.; (Assigned to MTIX Ltd., UK). Treating Materials with Combined Energy Sources. U.S. Patent 9605376 B2, 28 May 2017.

17. Heywood, D. (Ed.) Textile Finishing; Society of Dyers and Colourists: Bradford, UK, 2003.

18. Peters, R.H. Textile Chemistry; Elsevier: Amsterdam, The Netherlands; London, UK; New York, NY, USA, 1967; Volume 2, pp. 91-92.

19. Wang, M.Y.; Horrocks, A.R.; Horrocks, S.; Hall, M.E.; Pearson, J.S.; Clegg, S. Flame retardant textile back-coatings. Part 1: Antimony-halogen system interactions and the effect of replacement by phosphorus-containing agents. J. Fire Sci. 2000, 18, 265-294.

20. Tang, W.K.; Neill, W.K. Effect of flame retardants on pyrolysis and combustion of $\alpha$-cellulose. J. Polym. Sci. Part C 1964, 6, 65-81. [CrossRef]

21. Moncrieff, R.W. Man-Made Fibres, 6th ed.; Newnes-Butterworth: London, UK, 1975; pp. 194-200, ISBN 0408001291.

22. Hearle, J.W.S. Physical Properties of Textile Fibres, 2nd ed.; Textile Institute: Manchester, UK, 1975; pp. 1-50, ISBN 1870812417.

23. Colom, X.; Carrillo, F. Crystallinity changes in lyocell and viscose-type fibres by caustic treatment. Eur. Polym. J. 2002, 38, 2225-2230. [CrossRef]

24. Duchemin, B.; Thuault, A.; Vicente, A.; Rigaud, B.; Fernandez, C.; Eve, S. Ultrastructure of cellulose crystallites in flax textile fibres. Cellulose 2012, 19, 1837-1854. [CrossRef]

25. Ross, K.; Mazza, G. Characteristics of lignin from flax shives as affected by extraction conditions. Int. J. Mol. Sci. 2010, 11, 4035-4050. [CrossRef] [PubMed]

26. Gotoh, K. Surface functionalisation of synthetic textiles by atmospheric plasma. In Textile Finishing. Developments and Future Trends; Mittal, K., Bahners, T., Eds.; Scrivener Publishing LLC: Beverly, MA, USA, 2017; pp. 237-260.

27. Vesel, A.; Mozetic, M.; Strnad, S.; Peršin, Z.; Stana-Kleinschek, K.; Hauptman, N. Plasma modification of viscose textile. Vacuum 2009, 84, 79-82. [CrossRef]

28. Kan, C.W.; Yuen, C.W.M. Influence of low temperature plasma treatment on the properties of tencel and viscose rayon fibers. IEEE Trans. Plasma Sci. 2009, 37, 1615-1619. [CrossRef] 
29. Peršin, Z.; Vesel, A.; Kleinschek, K.S.; Mozetič, M. Characterisation of surface properties of chemical and plasma treated regenerated cellulose fabric. Text. Res. J. 2012, 82, 2078-2089. [CrossRef]

30. Kramar, A.D.; Žekić, A.A.; Obradović, B.M.; Kuraica, M.M.; Kostić, M.M. Study of interaction between nitrogen DBD plasma-treated viscose fibers and divalent ions $\mathrm{Ca}^{2+}$ and $\mathrm{Cu}^{2+}$. Cellulose 2014, 21, 3279-3289. [CrossRef]

31. Ibrahim, N.A.; Eid, B.M.; Abdel-Aziz, M.S. Effect of plasma superficial treatments on antibacterial functionalization and coloration of cellulosic fabrics. Appl. Polym. Sci. 2017, 392, 1126-1133. [CrossRef]

2018 by the authors. Licensee MDPI, Basel, Switzerland. This article is an open access article distributed under the terms and conditions of the Creative Commons Attribution (CC BY) license (http:/ / creativecommons.org/licenses/by/4.0/). 